\title{
Consequences of density-dependent heterotrophic feeding for a partial autotroph
}

\author{
Jason E. Tanner* \\ Department of Marine Biology, James Cook University, Townsville, Queensland 4811, Australia
}

\begin{abstract}
Population regulation in sessile clonal animals has been poorly studied. The prevailing paradigm is that competition is primarily for space, although this is changing. I use a laboratory flume experiment to show that particle capture by the marine intertidal zoanthid Palythoa caesia is negatively related to density (\% cover) and positively related to colony size. Using models of colony growth and subsequent population dynamics, which incorporate this density- and size-dependent feeding response, I then show that it is potentially an important component of population regulation. The other important vital rate for regulating population size is fission-as this species is clonal it can reproduce asexually by splitting into 2 or more daughter colonies. Fission rates decrease with density and increase with colony size. When both feeding and fission are density-dependent, model cover is regulated to just under $80 \%$, but when either process is made density-independent, population growth is exponential. Importantly, when no heterotrophic feeding is allowed, and all respiratory requirements must come from the translocation of photosynthetic products from symbiotic zooxanthellae, the model population rapidly becomes extinct, whereas eliminating photosynthesis decreases cover but allows the population to persist. The colony level model shows that individual growth rates of large colonies are increased at low densities, while those of small colonies are decreased at high densities.
\end{abstract}

KEY WORDS: Clonal organisms · Population regulation · Suspension feeding · Density-dependence · Growth model $\cdot$ Population model

\section{INTRODUCTION}

In sessile marine organisms, competition has traditionally been attributed to the need to obtain space in which to grow (e.g. Connell 1961, Lang 1973, Buss \& Jackson 1979, Lang \& Chornesky 1990). There has also been increasing attention paid to competition for food in high density aggregations, with evidence that reduced feeding rates at increased density place major restrictions on the growth rates of some individuals (e.g. bryozoans: Buss 1979, Okamura 1992; sponges: Buss \& Jackson 1981; mussels: Fréchette et al. 1992). The population level consequences of intraspecific

\footnotetext{
*Present address: SARDI Aquatic Sciences, PO Box 120, Henley Beach, South Australia 5022, Australia.

E-mail: tanner.jason@saugov.sa.gov.au
}

competition for food in sessile filter feeders has been the subject of some speculation (e.g. Fréchette et al. 1992, Okamura 1992), but has to my knowledge never been explicitly addressed.

Some groups of sessile marine invertebrates also have a means of escaping the full impact of competition for food that is unavailable to most animals, although it may simultaneously intensify competition for space. These species, such as many corals, sponges, giant clams and didemnid ascidians, contain symbiotic zooxanthellae or Prochloron, and thus are at least partially autotrophic. It has been well documented that some of the products of photosynthesis are indeed transferred to the animal host, and in some cases can provide the majority of the host's carbon requirements (e.g. Sebens 1977, Muscatine et al. 1981, Olson \& Porter 1985, Sorokin 1991, Fabricius \& Klumpp 1995). 
For other species, however, photosynthesis only provides a small component of the host's requirements, with heterotrophic feeding still providing the majority (e.g. Porter 1976, Muscatine et al. 1984, Lewis 1992, Fabricius \& Klumpp 1995). Thus, for such organisms it is of interest to determine just how important this ability to photosynthesise is in ameliorating the effects of competition for food. Another unique feature of this group of animals is that many frequently reproduce asexually through colony fission, and this ability can also have important consequences for demography (e.g. Highsmith 1982, Ryland et al. 1984, Karlson 1991, Hughes \& Tanner 2000).

In this paper, I report the results of a laboratory flume experiment examining the effects of both upstream density and colony size on particle capture rates of the intertidal zoanthid Palythoa caesia. Like many sessile marine invertebrates, $P$. caesia is a suspension feeder, and relies on ambient water flow to deliver food items, mostly plankton, to within the capture range of its tentacles. I then go on to combine these results with existing information on colony level population dynamics of $P$. caesia across a range of densities (Tanner 1997, 1999), and with published energetic data for the same species at the same location at which this study was conducted (Sorokin 1991). The energetic data include details on rates of carbon uptake through photosynthesis and heterotrophic feeding and loss through respiration. Using these 3 sets of information, I develop models of both individual colony growth and population dynamics. These models allow me to determine the potential importance of density-dependent feeding rates at both the individual colony and population levels. I also examine what effect changing the rates of photosynthesis, heterotrophy and respiration has on both colony growth and population dynamics using an extensive series of sensitivity analyses to examine the robustness of the models to the assumptions made.

Palythoa caesia is unusual in comparison to most other species in which population regulation has been studied as it is clonal and can therefore reproduce extensively via asexual fission. Subsequent to fission, 2 genetically identical colonies are also able to fuse back into a single colony. In previous studies (Tanner 1997, 1999, 2000) I showed that fission rates decreased as density increased, while fusion rates increased, and that the population studied appeared to be regulated at around $80 \%$ cover. The main demographic process responsible for this regulation was the production of small colonies from large individuals through fission, as density-dependent fusion had a minimal effect on population dynamics. Further to these results, I suggested that regulation was probably maintained by a combination of density-dependence in fission and growth rates, possibly due to a reduction in food availability as density increased. However, unlike the model presented in this paper, the previous models did not explicitly incorporate fission and growth, and thus this hypothesis could not be tested. The model developed here explicitly includes specific vital rates, and its purpose is to determine whether density-dependent feeding and fission do in fact have the potential to regulate population size.

\section{METHODS AND RESULTS}

\section{Feeding trials}

To determine the consequences of the density (\% cover) of surrounding colonies and colony size for feeding in the zoanthid Palythoa caesia, colonies were fed hydrated Artemia cysts in a laboratory flume. The flume was similar in design to that shown by Vogel \& LaBarbera (1978, their Fig. 1). The working section of the flume was $170 \mathrm{~cm}$ long, $30 \mathrm{~cm}$ wide and filled to a depth of $25 \mathrm{~cm}$. At the upstream end was a $10 \mathrm{~cm}$ long collimator made of $10 \mathrm{~mm}$ diameter PVC pipe, which filled the entire cross-section of the flume. Water was directed into the return pipe at the downstream end by a faceplate at an angle of $45^{\circ}$, and was moved by a propeller attached to a variable speed motor. The return pipe was constructed of $20 \mathrm{~cm}$ diameter PVC pipe. Overall, the entire system held approximately 2201 of water.

Colonies of Palythoa caesia were collected from the reef crest at Heron Island at the southern end of Australia's Great Barrier Reef, and held in flow-through aquaria for a minimum of $48 \mathrm{~h}$ prior to use in any experiment. Only colonies which appeared healthy and fed actively at the end of this period were retained for use. Each 45 min feeding trial involved placing a randomly selected colony (the focal colony) in the centre of the flume at the downstream end of the working section, and a variable number of colonies within $30 \mathrm{~cm}$ upstream of it. A total of $2 \mathrm{~g}$ hydrated Artemia cysts (microwaved for $1 \mathrm{~min}$ prior to hydration to prevent hatching) were added to the flume and allowed to circulate for 2 to $3 \mathrm{~min}$ to allow time for mixing to occur. To determine cyst concentrations, two $50 \mathrm{ml}$ water samples were then taken from near the bottom of the flume using a syringe, prior to the addition of the $P$. caesia. As this species is a nocturnal feeder, all colonies were kept in the dark and experiments were conducted at night with the aid of a red light, which did not appear to disturb them. At the end of each trial a photograph was taken of the layout of the colonies. The focal colony was then removed, gently washed in seawater to remove any cysts adhering to the colony surface and placed in a bowl of seawater to regurgitate 
any ingested cysts. The remaining colonies were then removed from the flume, and free-stream flow speed was measured by determining the time required for a plume of dye to travel $50 \mathrm{~cm}$. Egested cysts were counted $36 \mathrm{~h}$ after removing the focal colony from the flume, to obtain colony feeding rates. At this time, the number of polyps in each focal colony was also counted. Preliminary studies indicated that cysts were not egested for at least $6 \mathrm{~h}$, and that dissected colonies retained no cysts after $36 \mathrm{~h}$.

To ensure an approximately constant concentration of Artemia cysts throughout the study, the flume was emptied and rinsed between trials and refilled with unfiltered seawater pumped from the nearby reef slope. A total of 116 trials were conducted in October 1998, with focal colony sizes ranging from 4.5 to $47 \mathrm{~cm}^{2}$, and upstream densities from 0 to $99 \%$ cover. Water temperatures at this time ranged between 25 and $27^{\circ} \mathrm{C}$.

To determine the size of each focal colony, the photographs were traced and digitised, giving a measure of the colony's planar area (PA). The outlines of all upstream colonies were also digitised to determine upstream density (as \% cover of an area $20 \mathrm{~cm}$ wide, $30 \mathrm{~cm}$ long). Percent cover was used as a biologically relevant measure of density, as it integrates number of colonies and colony size in a natural way. Ingestion rates were originally analysed using generalised additive models (GAM, a form of non-linear regression) with a Poisson distribution (for count data, Hastie \&
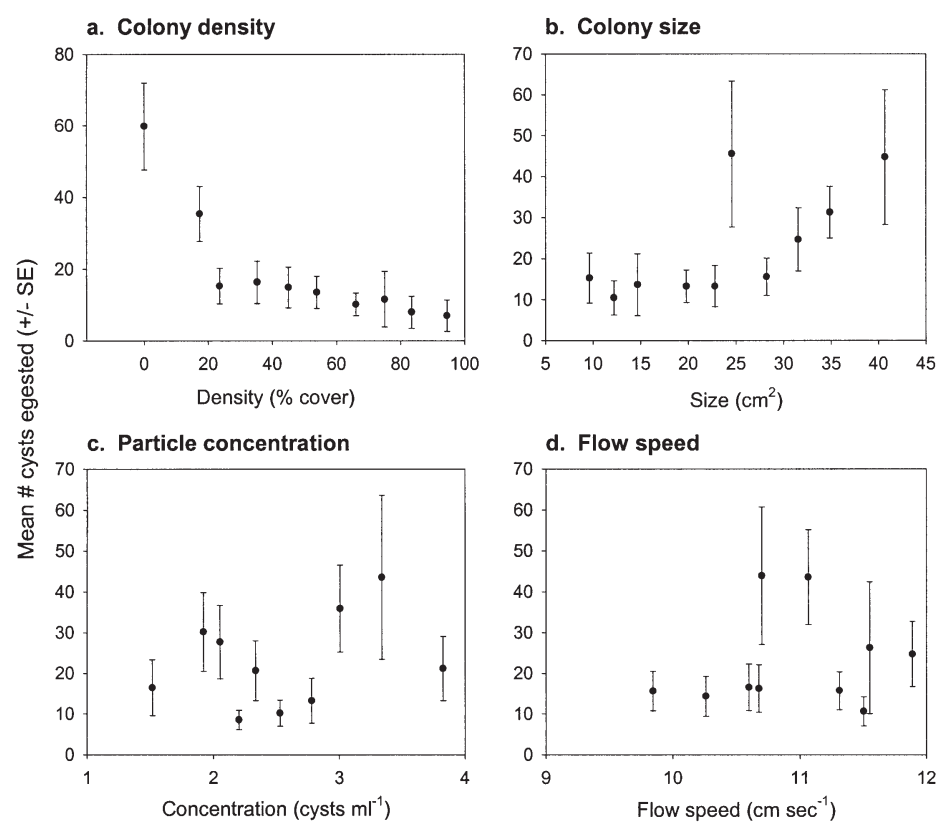

Fig. 1. Palythoa caesia. Relationship between colony ingestion rates and density, size, particle concentration and flow speed, for each variable taken independently. Means \pm SE are plotted for 10 approximately equal-sized groups of colonies
Table 1. Factors determining colony feeding rates in Palythoa caesia. ANOVA table for best fit GAM. $\mathrm{p} \ll 0.01$ in all cases

\begin{tabular}{|lrcc|}
\hline & df & Deviance & $\begin{array}{c}\text { \% variance } \\
\text { accounted for }\end{array}$ \\
\hline Total & 109 & 3515 & \\
Density & 4 & 1233 & 35 \\
Size & 4 & 529 & 15 \\
Concentration & 4 & 154 & 4.4 \\
Flow speed & 4 & 146 & 4.1 \\
\hline
\end{tabular}

Tibshirani 1990), with focal colony size, upstream density, concentration of Artemia (average concentration from the two $50 \mathrm{ml}$ water samples) and flow speed as predictors. The GAM was fit by using a forwardsbackwards stepwise method in S-plus (Insightful Corp., Seattle, WA), where the variable accounting for the greatest amount of variance was added to the model first, and the next best added at each step, checking that all variables were still necessary after each addition. Each variable in the GAM was fit using a cubic spline smooth with $4 \mathrm{df}$.

Looking firstly at the effect of each predictor variable on ingestion rates in isolation, we see that neighbours had a substantial influence (Fig. 1a). Ingestion rates decreased by $\sim 70 \%$ from 0 to $20 \%$ upstream cover, with only slight decreases thereafter. As expected, increases in colony size lead to increases in whole colony ingestion rates, although this occurred mainly for the larger colonies (Fig. 1b). Results for particle concentration and flow speed were much more erratic, with no obvious consistent trends (Fig. 1c,d).

Taking all 4 variables into account simultaneously, while all contributed significantly to the model fit, upstream density and colony size accounted for half of the variance in feeding rate, whereas particle concentration and flow speed only accounted for just over $4 \%$ each (Table 1). As previously, when colony density (\% cover) increased, feeding rate decreased monotonically (Fig. 2a), while feeding increased with colony size (Fig. 2b). Particle concentration varied little (2 to 4 cysts $\mathrm{ml}^{-1}$ ) and had a very minimal effect (Fig. 2c, although there was a mean decrease at high concentrations, the error bands encompass the case of no concentration effect). Flow speed also had little effect on ingestion over the narrow range (10 to $14 \mathrm{~cm}^{-1}$ ) examined, although there was a slight decrease at high flow (Fig. 2d). The GAM indicated that each variable entered into the model in an approximately linear fashion, so a generalised linear model (GLM, with Poisson distribution) 

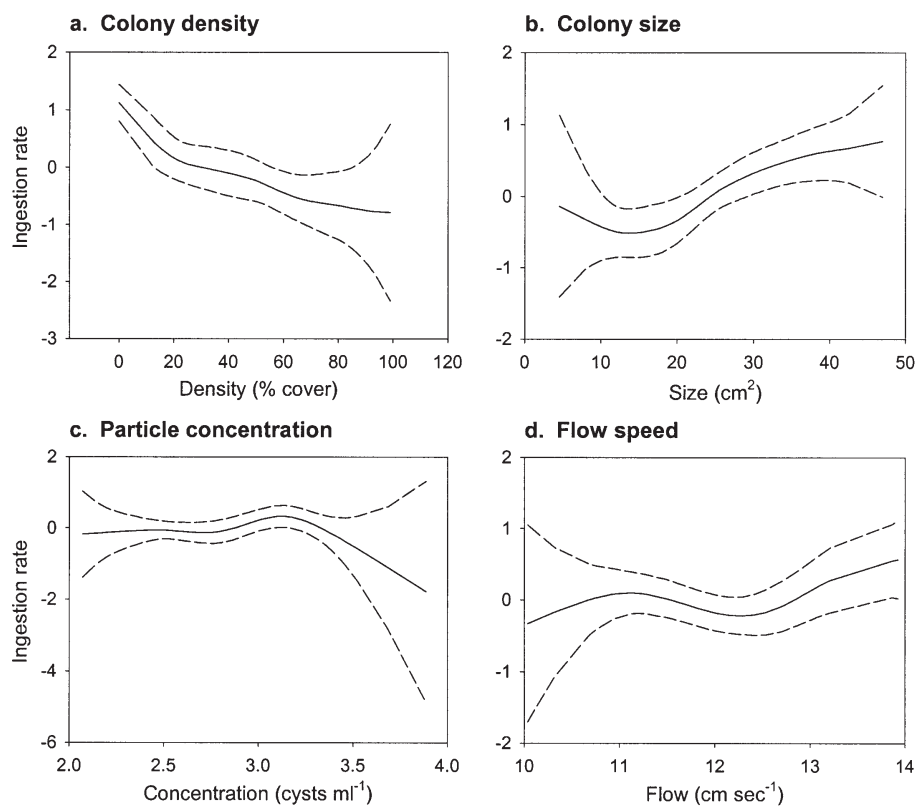

Fig. 2. Simultaneous influence on particle ingestion rates of Palythoa caesia of (a) population density (\% cover), (b) colony size, (c) Particle concentration and (d) flow speed. (-) represents the GAM fit, $(----) \pm 2 \times$ SE. As all 4 variables are involved in determining feeding rates, plotting the actual data obscures any relationship, and is therefore not included. Each panel represents the contribution of the associated variable to ingestion, log-transformed (to account for the Poisson distribution) and centred to a mean of zero

was fit to obtain an equation for modelling particle ingestion (and later colony growth) as a function of upstream density and colony size. Flow rate and food concentration were not included in this model as they only varied over a relatively small range, and are not examined in the growth models developed later. The resulting GLM accounted for $44.3 \%$ of the variance in feeding $(\mathrm{p} \ll 0.001)$, and gave the equation (symbols defined in Table 2):

$F_{\mathrm{e}}=\exp (2.86-0.0266 \times d+0.0423 \times P A)$

To determine the relationship between colony size measured as projected area from the photographs, and the number of polyps in a colony, linear regression was used. This resulted in the equation:

$$
\begin{gathered}
p=15.1+3.26 \times P A \\
\left(F=217, \mathrm{p} \ll 0.001, \mathrm{r}^{2}=0.67\right)
\end{gathered}
$$

\section{Colony growth model}

To determine the potential effects of density-dependence in heterotrophic feeding rates on colony growth, a model directly incorporating information from the above experiment was developed. This model was used to examine the sensitivity of colony growth to the different physiological parameters used, and to feed into a subsequent model of population dynamics. Sizeand density-dependent growth rates of individual colonies were calculated based on experimental ingestion rates, and data published by Sorokin (1991) on rates of heterotrophic carbon uptake, photosynthesis and respiration, as well as the biomass of individual polyps of Palythoa caesia. The colonies used by Sorokin (1991) were from the same reef as those used in the flume experiment presented here, although their exact collection location is unknown. The model tracks net carbon gain as the balance of heterotrophic feeding and photosynthesis versus respiration, and converts this to relative growth. Food uptake depends on colony density as found in the feeding experiment, while all 3 physiological rates also depend on colony size.

While Sorokin (1991) gives data on a per gram wet weight basis, photosynthesis was scaled to colony surface area as only the outer layer of the colony is exposed to light, and heterotrophic uptake was scaled to projected area to fit with the experimental data on feeding rates obtained above. Respiration was scaled to colony volume as a surrogate for biomass, although the use of surface area only produced slight quantitative changes to the

\begin{tabular}{|c|c|}
\hline Symbol & Definition \\
\hline$d$ & Density (\% cover) \\
\hline$F_{\mathrm{dd}}$ & Density-dependent ingestion rate $\left(\mu \mathrm{g} \mathrm{C} \mathrm{g} \mathrm{dry} \mathrm{wt}^{-1} \mathrm{~d}^{-1}\right)$ \\
\hline$F_{\mathrm{di}}$ & Density-independent ingestion rate \\
\hline$F_{\mathrm{e}}$ & Ingestion rate from flume experiment (Eq. 1, cysts $45 \mathrm{~min}^{-1}$ ) \\
\hline$F_{\mathrm{r}}$ & Ingestion rate of a colony with radius $2.25 \mathrm{~cm}$ (from Eq. 1) \\
\hline$F S$ & Ingestion rate from Sorokin (1991) $250 \mu \mathrm{g} \mathrm{C} \mathrm{g} \mathrm{dry} \mathrm{wt} \mathrm{t}^{-1} \mathrm{~d}^{-1}$ \\
\hline$P$ & Size-dependent photosynthetic rate $\left(\mu \mathrm{g} \mathrm{C} \mathrm{cm}{ }^{-2} \mathrm{~d}^{-1}\right)$ \\
\hline$P A$ & Colony planar (projected) area $\left(\mathrm{cm}^{-2}\right)$ \\
\hline$p$ & Number of polyps in colony (Eq. 2) \\
\hline$p_{\mathrm{g}}$ & Number of polyps g dry wt ${ }^{-1}$ (from Sorokin 1991) \\
\hline$p_{\mathrm{r}}$ & Number of polyps in a colony with radius $2.25 \mathrm{~cm}$ \\
\hline$P S$ & Photosynthetic rate from Sorokin (1991) $190 \mu \mathrm{g} \mathrm{C} \mathrm{g} \mathrm{dry} \mathrm{wt}{ }^{-1} \mathrm{~d}^{-1}$ \\
\hline$r$ & Colony radius $(\mathrm{cm})$ \\
\hline$R$ & Size-dependent respiration rate $\left(\mu \mathrm{g} \mathrm{C} \mathrm{cm} \mathrm{cm}^{-2} \mathrm{~d}^{-1}\right)$ \\
\hline$R G R$ & Relative daily growth rate \\
\hline$R S$ & Respiration rate from Sorokin (1991) $160 \mu \mathrm{g} \mathrm{C} \mathrm{g} \mathrm{dry} \mathrm{wt}{ }^{-1} \mathrm{~d}^{-1}$ \\
\hline$S A$ & Surface area $\left(\mathrm{cm}^{2}\right)$ \\
\hline$S A_{\mathrm{e}}$ & Surface area of model colony \\
\hline$S A_{\mathrm{r}}$ & Surface area of colony with radius $2.25 \mathrm{~cm}$ \\
\hline$V$ & Colony volume $\left(\mathrm{cm}^{3}\right)$ \\
\hline$V_{\mathrm{e}}$ & Volume of model colony \\
\hline$V_{\mathrm{r}}$ & Volume of colony with radius $2.25 \mathrm{~cm}$ \\
\hline
\end{tabular}

Table 2. Symbols used 
results (data not shown). To perform these conversions, it was assumed that colonies were shaped as a hemiellipsoid, with a circular cross-section in the horizontal plane, and a height of half the basal radius. Thus for a colony of radius $r$, the projected (or planar) area $(P A)$, surface area $(S A)$ and volume $(V)$ are:

$$
\begin{gathered}
P A=\pi r^{2} \\
S A=\pi r^{2}+\frac{\pi r^{2}}{4 \sqrt{3}} \log \frac{2+\sqrt{3}}{2-\sqrt{3}} \\
V=\frac{\pi r^{3}}{3}
\end{gathered}
$$

There was only slight qualitative variation in the model output if different shapes, ranging from a flat sheet to a hemisphere, were used (data not shown).

Sorokin (1991) gives rates for photosynthesis of $190 \mu \mathrm{g} \mathrm{C}$ g dry colony $\mathrm{wt}^{-1} \mathrm{~d}^{-1}$, respiration of $160 \mu \mathrm{g} \mathrm{C}$ gdry colony $\mathrm{wt}^{-1} \mathrm{~d}^{-1}$, and total heterotrophic feeding of $250 \mu \mathrm{gC}$ gdrycolony $\mathrm{wt}^{-1} \mathrm{~d}^{-1}$. These measurements were all made on colonies of 3 to $6 \mathrm{~cm}$ diameter. To convert photosynthesis $(P)$ to a surface-areadependent rate, and respiration $(R)$ to a volumedependent rate, the following equations were used (assuming the above size-independent rates applied to a reference colony of $2.25 \mathrm{~cm}$ radius - the midpoint of the size range used to obtain them; symbols defined in Table 2):

$$
\begin{aligned}
& P=\frac{S A_{\mathrm{e}}}{S A_{\mathrm{r}}} \times \frac{p_{\mathrm{r}}}{p_{\mathrm{g}}} \times P S \\
& R=\frac{V_{\mathrm{e}}}{V_{\mathrm{r}}} \times \frac{p_{\mathrm{r}}}{p_{\mathrm{g}}} \times R S
\end{aligned}
$$

The number of polyps g dry $\mathrm{wt}^{-1}\left(p_{\mathrm{g}}\right)$ was calculated from the number of polyps in $1 \mathrm{~g}$ of wet tissue (Eq. 6), and the ratio between dry and wet weights of 0.45:1 given by Sorokin (1991).

Size- and density-dependent food consumption in terms of carbon uptake were obtained by combining Eq. (1) from experimental work on densitydependent feeding rates, with Sorokin's (1991) data on feeding, assuming that in both experiments colonies of the same size had the same food intake when neighbours were absent. This resulted in the Equation (symbols defined in Table 2):

$$
F_{\mathrm{dd}}=\frac{F_{\mathrm{e}}}{F_{\mathrm{r}}} \times \frac{p_{\mathrm{r}}}{p_{\mathrm{g}}} \times F S
$$

To determine the consequences of making feeding density-dependent, we also need a density-independent version of Eq. (8):

$$
F_{\mathrm{di}}=\frac{\exp (2.01+0.043 \times P A)}{\exp (2.01+0.043 \times 15.9)} \times \frac{p_{\mathrm{r}}}{p_{\mathrm{g}}} \times F S
$$

This feeding rate is derived from data on colonies at all densities by using GLM to obtain an expression for ingestion as a function of colony size only (the density independent equivalent of Eq. 1). Data from all colonies and not just those at zero upstream density were used, as the latter would only allow a comparison between colony growth rates in a population of closely spaced individuals and a population where colonies were sufficiently spaced for there to be no feeding interactions. Combining the equations for feeding, photosynthesis and respiration, and assuming for the moment that all excess carbon is used for growth (effectively giving maximum potential growth), we obtain a relative daily growth rate $(R G R)$ :

$$
R G R=\frac{F+P-R}{610 \times p}
$$

where 610 is the biomass of a single polyp in $\mu \mathrm{g} \mathrm{C}$ (Sorokin 1991). Ingestion rate $F$ is either $F_{\mathrm{dd}}$ or $F_{\mathrm{di}}$, depending on the situation being modelled. As responses of Palythoa caesia in the laboratory are being extrapolated to a field situation, and it is assumed that feeding rates in the flume experiment are the same as feeding rates in Sorokin's (1991) study, a comprehensive series of sensitivity analyses are conducted to determine the likely consequences of any errors in the model.

The density-dependent model of colony growth indicates that the highest relative growth rates are achieved by small colonies at low densities (Fig. 3a). At low density, as colony size increases, growth first decreases, and then increases slightly for the largest colonies. Conversely, at high densities, small colonies fare poorly, intermediate-sized individuals do the best, and the largest colonies actually shrink (as observed in the field; Tanner 1997). At all sizes, colony growth rates decrease as density increases. Replacing the den- a. Density-dependent

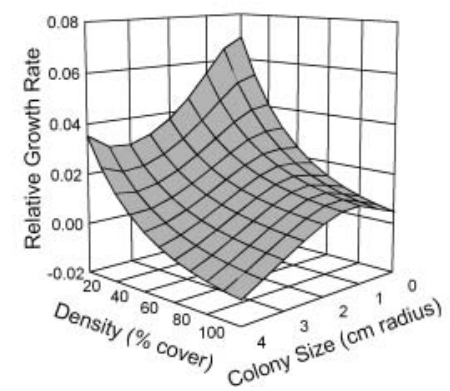

b. Density-independent

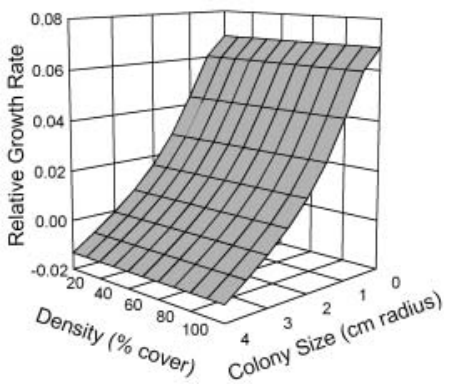

Fig. 3. Comparison of relative colony growth rates for Palythoa caesia derived from the model under the assumptions of (a) densitydependent and (b) density-independent feeding 
sity-dependent feeding equation (Eq. 8) by the density-independent equation (Eq. 9) shows that increasing density affects Palythoa caesia by decreasing the growth of small colonies, but increasing that of large colonies (compare Fig. 3b to 3a).

Increasing the base level of food consumption (by increasing FS in Eq. 8), results in an exaggeration of the density effects, while decreasing it reduces the importance of density (Fig. 4). At the same time, the extent of the size effects changes in the opposite direction, i.e. when heterotrophic feeding is reduced there is a larger size effect on colony growth. As would be expected, not only does a reduction in feeding change the shape of the growth curve, but it also consistently moves it down, and results in a greater size range of colonies shrinking. Increasing photosynthesis in a similar way results in the peak in growth of intermediate colonies at high densities and the trough at low densities, becoming more pronounced, while reducing photosynthesis smooths both of these features out (Fig. 5). Changes in the rate of photosynthesis do not influence the effect of density on colony growth, as photosynthesis is not density-dependent. Finally, with high respiration rates, density and colony size both have substantial effects on growth, which decrease as respiration rate decreases (Fig. 6). a. $\mathrm{FS}=\mathbf{3 0 0}$

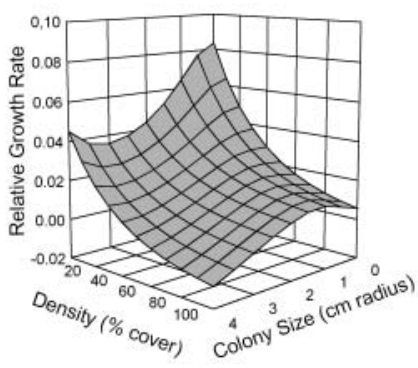

c. $\mathrm{FS}=100$

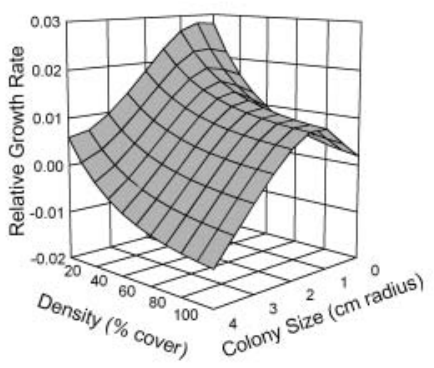

a. $\quad P S=300$

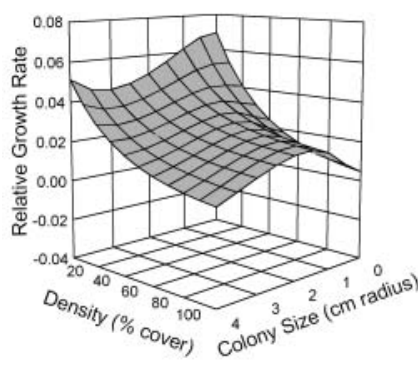

c. $P S=100$

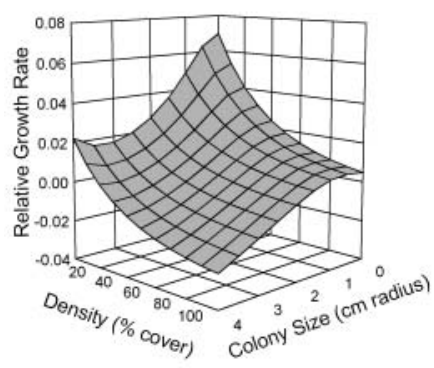

b. $\quad P S=200$

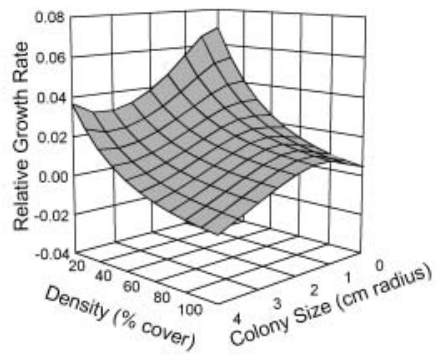

d. $\quad P S=0$

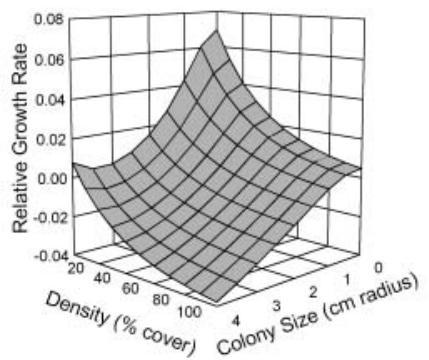

Fig. 5. Influence of altering the rate of photosynthesis on modelled Palythoa caesia colony growth. PS is the base photosynthetic rate of a solitary $16 \mathrm{~cm}^{2}$ colony in $\mu \mathrm{g} \mathrm{C} \mathrm{g}^{-1} \mathrm{~d}^{-1}$ (final term in Eq. 6). Fig. 3a gives the case when $P S=190$ a. $\mathbf{R S}=\mathbf{3 0 0}$

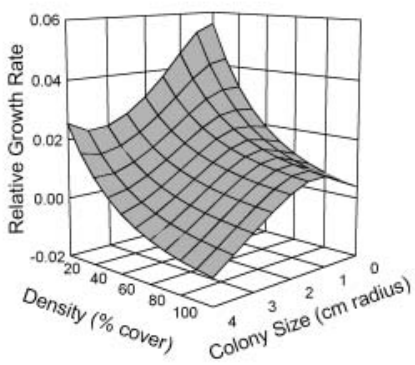

d. $\quad F S=0$

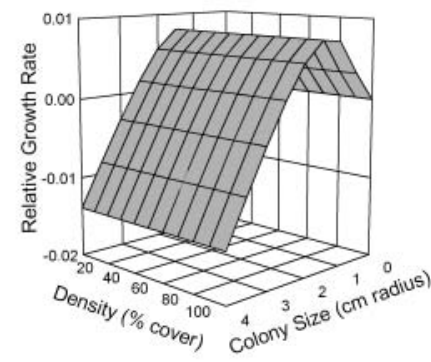

c. $R S=100$

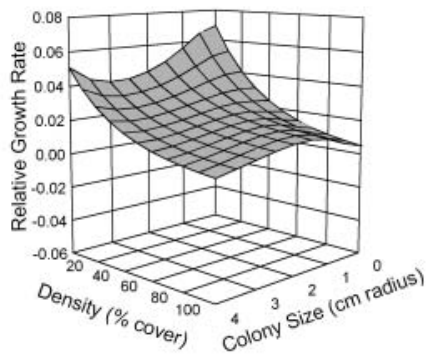

b. $\mathrm{RS}=\mathbf{2 0 0}$

d. $R S=0$

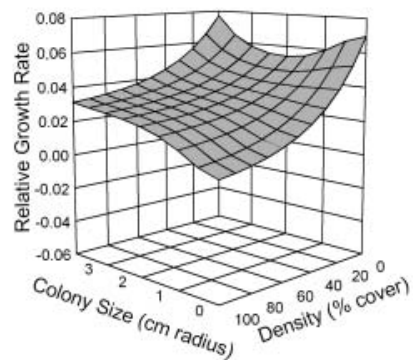

Fig. 4. Influence of altering heterotrophic feeding rates while maintaining size- and density-dependence on modelled colony growth of Palythoa caesia. FS is the ingestion rate of a solitary $16 \mathrm{~cm}^{2}$ colony in $\mu \mathrm{C} \mathrm{g}^{-1} \mathrm{~d}^{-1}$ (final term in Eq. 8). Fig. 3a gives the case when $F S=250$. Note change in scale on the vertical axis
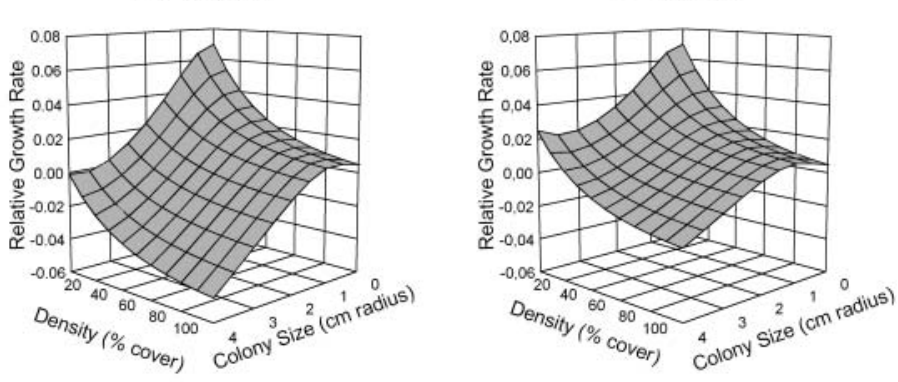

Fig. 6. Influence of altering respiration rate on modelled colony growth of Palythoa caesia. $R S$ is the respiration rate in $\mu \mathrm{g} \mathrm{C} \mathrm{g}^{-1} \mathrm{~d}^{-1}$ for a solitary $16 \mathrm{~cm}^{2}$ colony (final term in Eq. 7). Fig. 2a gives the case when $R S=160$. Note the change in orientation of the axes in (d) 


\section{Population dynamics model}

The influence of density-dependence in colony feeding rates on population regulation was examined by combining the above equations into a simulation model of population dynamics. This model was also used to determine how sensitive population dynamics are to changes in feeding, photosynthesis and respiration rates (thus, also changes or errors in the model assumptions). The model kept track of the number of colonies in each of 1200 size classes in a $1 \mathrm{~m}^{2}$ area, with colonies undergoing growth, mortality, fission and fusion as a function of size and density. Maximum observed size of nearly 2000 colonies in the field was $12399 \mathrm{~mm}^{2}$. Based on this, model sizes ranged from $<10$ to $\geq 12000 \mathrm{~mm}^{2}$ (in $10 \mathrm{~mm}$ increments). Each simulation commenced with 10 colonies in size class 1 , which were first exposed to sizeand density-dependent mortality (probabilities given in Fig. 2 of Tanner 1997), with the survivors growing in size over 1 mo (28 d) according to Eq. (10) for RGR (multiplied by 28). After growth, colonies also underwent fission and fusion according to the probabilities given in Tanner (1997; Figs. 3 \& 4). All simulations were carried out for 2000 iterations (167 yr), although unless exponential growth occurred, equilibrium was always attained within the first 500. Except for simulations explicitly looking at the effects of larval recruitment, all population growth is by asexual fission, and hence involves an increase in the number of colonies, but not the number of genets (i.e. genetically distinct individuals). Previous models (Tanner 1999) indicated that recruitment was not important for population dynamics once an area was colonised. Indeed, mean recruitment was only 0.45 colonies $\mathrm{m}^{-2} \mathrm{yr}^{-1}$, with almost complete mortality after 8 mo (Tanner 1997, 1999).

In the initial phases of the original simulation, population growth was very high, with density reaching $77 \%$ cover within 18 yr (Fig. 7a). After this time, cover oscillated slightly between about 76 and $78 \%$, due to time lags associated with the 1 mo iteration period in the model (i.e. model colonies do not respond to gradual changes in density, but to the accumulated change over $1 \mathrm{mo}$ ). Decreasing this period resulted in a smoothing of these oscillations, while increasing it exaggerated them, until they became unstable and caused extinction with a 1 yr iteration period (data not shown). While I only present simulations showing $\%$ cover, similar patterns always appeared for the number of colonies. If observed colony growth rates over a 1 yr period are used (derived from Tanner 1997), initial population growth is slower, and the oscillations are longer, but equilibrium population size is still $~ 80 \%$ (Fig. 7b).
Of course, feeding and photosynthesis are unlikely to be constant, and will depend on the vagaries of food supply and cloud cover (among other variables). Respiration is less likely to fluctuate, although may still vary somewhat with environmental conditions. Adding independent random variation to either feeding or photosynthesis (multiplying them by $\delta$, a uniformly distributed random variable between 0.5 and 1.5, i.e. $\delta \sim U[0.5,1.5])$, gave similar results (Fig. $7 \mathrm{c}$ ), with random variation in photosynthesis causing greater fluctuations than in feeding. Further increasing the size of the random fluctuations by making $\delta \sim U[0,2]$ resulted in substantially slower initial growth, with many episodes of near extinction for random feeding but not photosynthesis, and wider fluctuations in the 'equilibrium' phase for both processes. When both feeding and photosynthesis were multiplied by $\delta \sim U[0,2]$ extinction invariably occurred (Figs. $7 \mathrm{~d} \& 8 \mathrm{a}$ ). In most cases, the addition of random variation slightly increased the mean cover over the last 1000 iterations, except when photosynthesis fluctuated over the greater range, when mean cover decreased (Fig. 8a).

Eliminating density-dependence in food consumption by using Eq. (9) in the model in place of Eq. (8) (but retaining density-dependence in mortality, fission and fusion), resulted in exponential growth (Fig. 8b), indicating that at least in the model density-dependence in feeding is necessary to regulate population size. Similarly, making fission rates, but not feeding, densityindependent also resulted in exponential growth. In

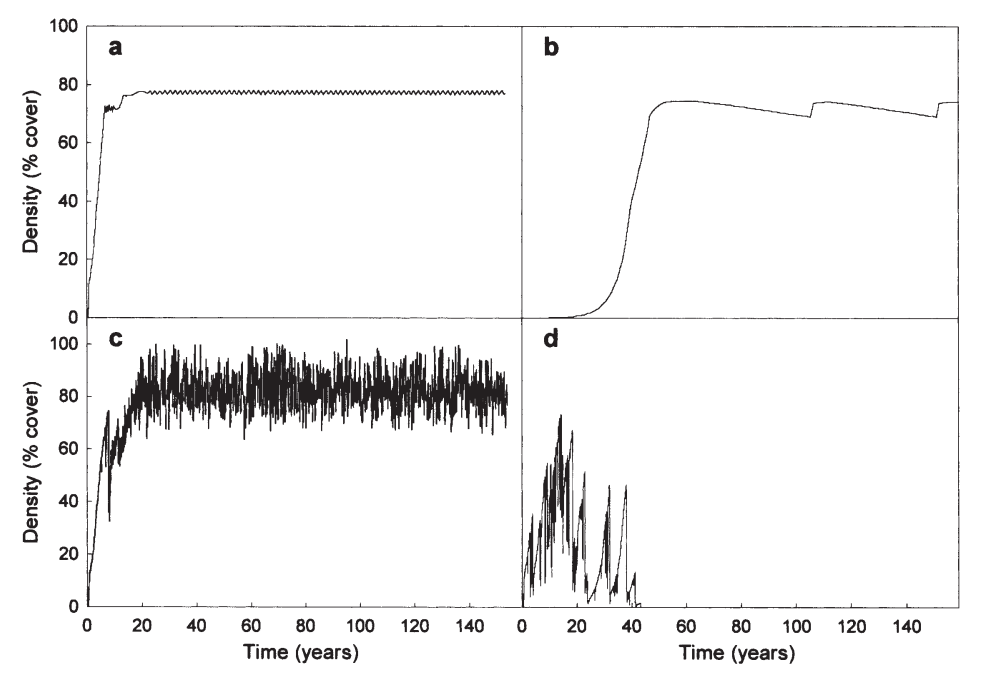

Fig. 7. Palythoa caesia population trajectories for models incorporating density-dependent feeding: (a) original model with growth dependent on feeding; (b) model with observed colony growth rates from Tanner (1997); (c) typical example showing the influence of stochastic variation in feeding and photosynthesis (obtained by multiplying FS and PS by independent uniformly distributed random variables $\delta \sim U[0.5,1.5]$ ); (d) typical example showing the influence of multiplying $F S$ and $P S$ by independent uniformly distributed random variables $\delta \sim U[0,2]$ 

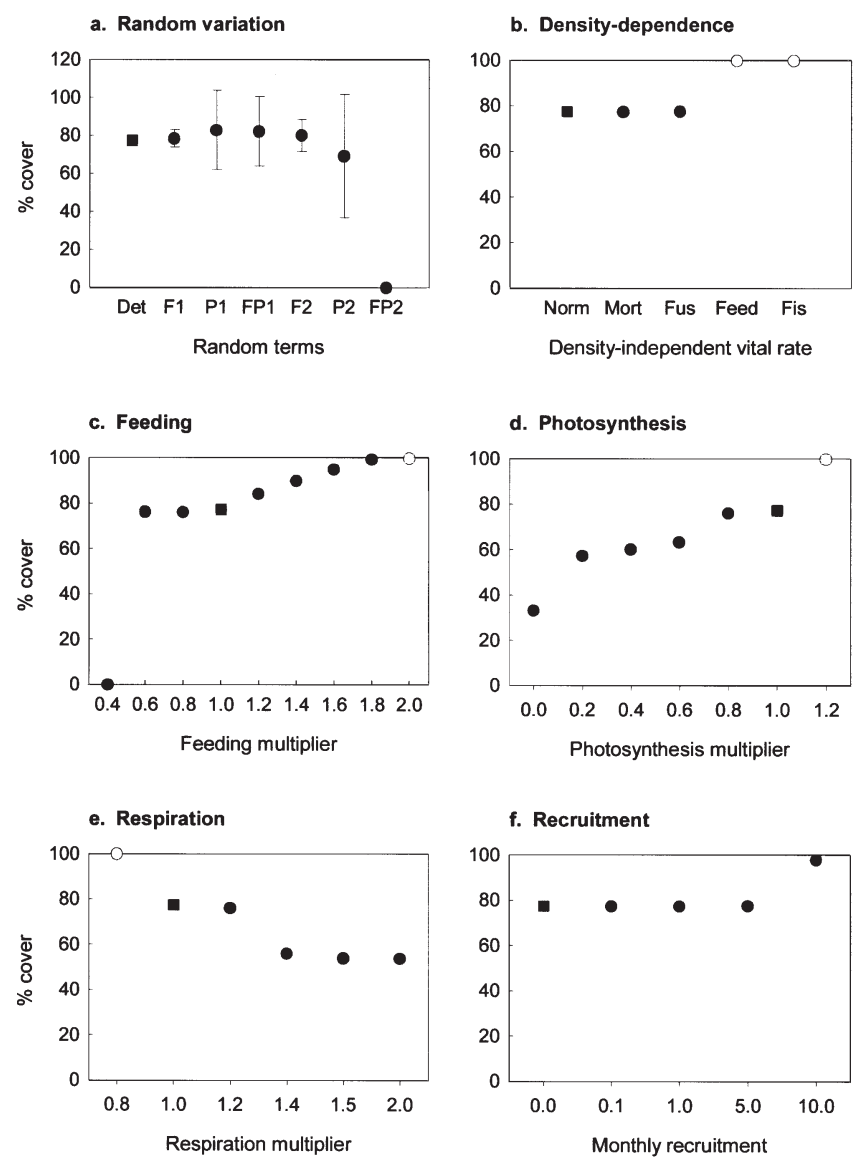

Fig. 8. Palythoa caesia sensitivity of the population model to changes in major model parameters. (घ) Values for the original unmodified model with colony growth as in Fig. 2a, (•) responses to changes in the parameter investigated, ( $(0)$ exponential growth to infinity for that parameter value (indicating that under the model assumptions, that value is not biologically realistic). Plotted values are means of the final 500 iterations and error bars in (a) indicate the range of values observed. Values on the $X$-axis for photosynthesis, respiration and feeding are multipliers for $P S, R S$ and $F S$ respectively. For the addition of random variation (a), Det indicates the base deterministic model, F1, P1 and FP1 indicate that FS, PS and both $F S$ and $P S$ are multiplied by $\delta \sim U[0.5,1.5]$, while F2, P2 and FP2 indicate that $\delta \sim U[0,2]$. (b) Density-independent vital rates are mortality (Mort), fusion (Fus), feeding (Feed) and fission (Fis), with Norm being the model with all rates densitydependent

contrast, density-dependence in mortality and fusion had little influence on population dynamics, and making these processes density-independent did not change cover appreciably.

Slightly reducing the overall rate of feeding (by multiplying $F$ by a constant) had very little effect on population density (Fig. 8c). However, substantial reductions in food uptake (by about $1 / 2$ ) resulted in population extinction, indicating that Palythoa caesia does not have the potential to be fully autotrophic under these conditions. Conversely, increasing feeding rates resulted in higher cover. Increasing the feeding rate by a factor of 2 or more resulted in cover exceeding $100 \%$, which is impossible for this species, suggesting that if feeding does actually occur naturally at this rate, not all the resources consumed are directed towards colony growth.

Similar modifications to the rate of photosynthesis produce much more erratic behaviour (Fig. 8d). Increasing $P$ by a factor of 1.2 or more results in exponential population growth, while slight reductions have little effect on cover. Further decreases result in a slow decline in cover. Finally, changes in the rate of respiration produce opposite results to changes in photosynthesis (Fig. 8e). Slight reductions in respiration produce exponential growth, whereas increases slowly reduce cover.

All of the above simulations were run without recruitment, so population growth was solely due to asexual fission. Adding a low level of external recruitment to the system did not change the model behaviour substantially (Fig. 8f). In all cases recruits were added to the first size class at the beginning of each iteration. Cover did not change at all until recruitment reached a level of 10 colonies $\mathrm{mo}^{-1}$, when it increased. Given the very low rate of observed recruitment $\left(0.04 \mathrm{~m}^{-2} \mathrm{mo}^{-1}\right.$, Tanner 1999), it is obvious that recruitment does not play an important role in the colony level dynamics of established aggregations, although it would have important consequences for the genetic structure of the population.

\section{DISCUSSION}

The models developed here support the prediction that density-dependent feeding rates, and therefore growth, play an important role in regulating the population size of Palythoa caesia. This adds further support to the suggestion that density-dependent food consumption, and not just competition for space, has a potentially important role in regulating the dynamics of sessile organisms (e.g. Fréchette et al. 1992, Okamura 1992). The other important process appears to be fission, which probably decreases as density increases as a result of direct spatial competition. Thus, population regulation appears to be a result of competition for both food and space, rather than for one resource alone. Density-dependence in fission rates may also occur if the slower growth rates at high densities result in the distribution of colonies within a size class being skewed towards smaller colonies, combined with the previously documented decrease in fission rates as colony size decreases (Tanner 1997).

While the link between feeding and growth has not been explicitly established for Palythoa caesia, it has 
been for several other sessile marine species, and it can reasonably be assumed. Okamura (1992) demonstrated that changing flow rates changed both food capture and growth in the same way for bryozoans, while Fréchette et al. (1992) showed directly that decreased food availability through addition of upstream competitors could cause mussels to decrease in body size. For soft corals, Fabricius et al. (1995) also showed that flow had the same effects on feeding as it did on growth. Thus, while feeding rate is unlikely to be the only determinant of growth for $P$. caesia, it seems logical to expect it to play an important role.

Of particular note is how similar the population trajectory for the model developed here is to that demonstrated by earlier models (Tanner 1999, 2000), which showed similar logistic type growth to an equilibrium (either deterministic or stochastic) cover of approximately $80 \%$. While these models are unfortunately not completely independent, as the mortality, fission and fusion rates used here were derived from the same experiment as the transition rates between size classes used in the previous models, colony growth rates were derived entirely independently. As colony growth was one of the most important determinants of the model populations behaviour, as indicated by the influence of eliminating density-dependence in growth compared to other vital rates (Fig. 8b), the similarity between the different models increases confidence in their predictions. The explicit incorporation of fission into the model also strengthens the evidence for its importance.

The decrease in particle capture as upstream density increases is in accordance with most other studies of feeding in sessile suspension feeders (e.g. Okamura 1992, Anthony 1997, Sebens et al. 1997). These negative effects can arise either through food depletion (e.g. Fréchette et al. 1992), or a decrease in particle flux due to a decrease in flow speeds (Sebens et al. 1997). The reverse may also occur, with the presence of neighbours increasing particle capture by slowing water flow and reducing shear stress (e.g. Okamura 1985, 1988, McFadden 1986). Thus, it is possible that reduced ingestion rates in Palythoa caesia are due to either food depletion by upstream colonies, or changes in the flow regime.

One of the assumptions made by Sorokin (1991) was that Palythoa caesia has $12 \mathrm{~h} \mathrm{night}^{-1}$ available for feeding. However, as most colonies are intertidal, including those studied here, they will have less time. As feeding is impossible at low tide, heterotrophic consumption will probably be less than assumed, resulting in a shift in growth rates towards those predicted for reduced feeding (see Fig. 4). Other assumptions of the model are that laboratory derived rates of feeding, photosynthesis and respiration are similar to what occurs in the field. These rates may err on the high side as conditions are favourable in terms of food and light availability, but colonies may also have been stressed in the laboratory and not fully active. I have also assumed that feeding rates of isolated colonies are directly comparable between this study and that of Sorokin (1991). As the latter used radioactively labelled cultures of live Artemia, Brachionus and Aplisia, apparently in still water, this may not be the case. However, sensitivity analysis indicates that substantial differences in feeding under these different sets of conditions would need to occur before major changes in model output would result (Figs. 4 \& 8c).

Probably the most tenuous assumption is that feeding is always density-dependent, which would require smooth linear flow over the substrate. In reality, there are times when wave action causes turbulent flow, and therefore mixing of the food depleted boundary layer with water above it, reducing the potential for food depletion to occur. Small-scale turbulence induced by neighbouring colonies in particular has been shown to be important in modifying food availability to benthic suspension feeders (Fréchette et al. 1989, Monismith et al. 1990, O'Riordan et al. 1993, Eckman \& Okamura 1998). Okamura (1992) showed that growth and feeding responses of bryozoans at different densities in smooth and turbulent flow were very similar. Thus, even in turbulent flow, Palythoa caesia may experience some density-dependence in feeding rates. As turbulence increases to levels that reduce this densitydependence, it is likely that particle capture is going to decrease anyway due to interference by water motion (e.g. Sebens \& Johnson 1991, Fabricius et al. 1995, Anthony 1997, Sebens et al. 1998), again moving the field situation towards the examples of reduced food intake shown in Figs. 4 \& 8c. Further support for the importance of density-dependent feeding is provided by field studies of mussel growth which show animals on the edge of patches grow faster, ostensibly due to higher food supply (Okamura 1986, Newell 1990). Thus, a large proportion of food intake may occur under conditions where feeding will be densitydependent.

Under favourable conditions when growth rates are predicted to be high, and possibly at other times, some of the resources which the model allocates to growth will be diverted to reproduction. There is little information available on how resources are allocated between growth and reproduction in any colonial cnidarians. For scleractinian corals, Edmunds \& Davies (1989) suggest that less than $50 \%$ of photosynthetically fixed carbon goes to somatic growth, and Szmant (1991) determined that reproduction required carbon equivalent to between 15 and $45 \%$ of respiratory demand. If this later range applies to Palythoa caesia, 
then approximately the equivalent of 12 to $38 \%$ of photosynthesis will be required for reproduction during the period in which oogenesis occurs. This would only result in slight reductions in colony and population growth rates (e.g. Fig. 4c shows the situation for a $47 \%$ decrease in photosynthesis, which would be the same if $47 \%$ was diverted to reproduction), and appears to be well within the ability of most colonies to sustain. In another study on scleractinian corals, Falkowski et al. (1984) reported that between 6 and $50 \%$ of translocated carbon was released as mucous, larvae and dissolved organic matter (DOM). P. caesia appears to release much less mucous than most corals (pers. obs.) but its rate of release of DOM is unknown.

At lower levels of heterotrophic feeding, growth may be constrained by a lack of resources other than carbon, particularly nitrogen. While it has been demonstrated that 97 to $99 \%$ of carbon and about $96 \%$ of nitrogen is translocated to the scleractinian coral host by zooxanthellae (Falkowski et al. 1984), the C:N ratio of this translocated material is considerably higher than in coral tissue, meaning that this may only represent a small fraction of the host's nitrogen requirements. Falkowski et al. (1984) found that translocated products had $\mathrm{C}: \mathrm{N}$ ratios between 10 and 30:1, while coral tissue was around 6.5:1. As a consequence, when other sources of nitrogen are not available, photosynthetic carbon is probably used mainly as an energy source, and not for growth. As a likely result of nitrogen limitation, Edmunds \& Davies (1989) found that some $67 \%$ of photosynthetic carbon was excess energy for a small-polyped species of scleractinian coral.

There is currently some debate about the relative roles of colony volume and surface area in determining respiration rates. Helmuth et al. (1997b) show that the mass flux can vary greatly according to colony shape. Mass flux can be an important determinant of respiration rates (e.g. Dennison \& Barnes 1988, Shick 1990), although this will depend on whether the kinetic rate of respiration exceeds what can be supported by the flux of materials across the colony surface (Sanford \& Crawford 2000). Given the simple and fairly flat shape of Palythoa caesia, there is little difference between model results for kinetically controlled respiration (i.e. respiration scales with biomass or volume) and mass flux controlled respiration (scaled to surface area) (data not shown). Therefore the method chosen to estimate respiration in the model should not be problematic.

The ratios between the different metabolic rates used in the above models are similar to those for scleractinian corals, but substantially different to those for octocorals (soft corals) (Sorokin 1991, Fabricius \& Klumpp 1995). Thus, the general conclusions potentially extend to at least some scleractinians, but proba- bly not to octocorals. Octocorals tend to have much slower metabolic rates, with photosynthesis making up a greater component of their energy intake - about double their respiratory requirements. Most symbiotic octocorals only obtain about 20 to $30 \%$ of their respiratory requirements from heterotrophic sources, although obviously asymbiotic species must obtain their entire requirements externally.

Despite the significant contributions made by photosynthesis to Palythoa Caesia's respiratory requirements, density-dependence in heterotrophic food capture still proved to be highly important in the model, suggesting this could severely limit both colony and population growth. If some photosynthetic carbon is wasted due to lack of nitrogen from other sources, or carbon is used for other purposes such as reproduction, these results are still likely to hold (see Fig. 8b). Due to the 3-dimensionally complex nature of many hard coral species, food depletion may be less of a problem for them than for P. caesia, which has a much less complex shape. However, it has been documented that particle capture rates can be density-dependent even in these more complex forms, and that food depletion can occur even within a colony (Helmuth et al. 1997a). Octocorals are unlikely to be regulated by densitydependent feeding as they rely on heterotrophic food consumption to a much lesser extent than do either $P$. caesia or hard corals (e.g. Sorokin 1991, Fabricius \& Klumpp 1995, Fabricius et al. 1995), and they tend to have more open morphologies which may reduce interference in feeding.

The hypothesis that density-dependent growth and fission, linked at least in part to density-dependent food consumption, regulate the population size of Palythoa caesia is supported by the model developed here. Importantly, while a large number of assumptions were made about colony shape, how metabolic rates scaled with size and how laboratory results translate to more natural field situations, the final model developed produced realistic behaviour which was very similar to that seen in previous models (Tanner 1999, 2000). Sensitivity analyses (Fig. 8) showed that minor (and in some cases major) departures from many of these assumptions produced only slight changes in population dynamics. In particular, assumptions about colony shape were unimportant (data not shown). Evidence that competition for food in suspension feeding marine invertebrates is potentially important to individual colonies is becoming increasingly common (e.g. Buss 1979, Fréchette et al. 1992, Okamura 1992, Anthony 1997, Sebens et al. 1997). By linking colony growth and feeding with population dynamics, this study has shown that such competition might be one of the primary mechanisms of population regulation. 
Acknowledgements. I would like to thank K. Anthony and M. Bergenius for help with this work, and R. Karlson, D. Levitan and the anonymous reviewers for very helpful comments on earlier versions of the manuscript. Funding was provided by ARC grants. This is contribution no. 179 of the Coral Ecology Group at James Cook University.

\section{LITERATURE CITED}

Anthony KR (1997) Prey capture by the sea anemone Metridium senile (L.): effects of body size, flow regime, and upstream neighbors. Biol Bull 192:73-86

Buss LW (1979) Bryozoan overgrowth interactions - the interdependence of competition for space and food. Nature 281:475-477

Buss LW, Jackson JBC (1979) Competitive networks: nontransitive competitive relationships in cryptic coral reef environments. Am Nat 113:223-234

Buss LW, Jackson JB (1981) Planktonic food availability and suspension-feeder abundance: evidence of in situ depletion. J Exp Mar Biol Ecol 49:151-161

Connell JH (1961) Effects of competition, predation by Thais lapillus and other factors on natural population of the barnacle Balanus balanoides. Ecol Monogr 31:61-104

Dennison WC, Barnes DJ (1988) Effect of water motion on coral photosynthesis and calcification. J Exp Mar Biol Ecol 115:67-77

Eckman JA, Okamura B (1998) A model of particle capture by bryozoans in turbulent flow: significance of colony form. Am Nat 152:861-880

Edmunds PJ, Davies PS (1989) An energy budget for Porites porites (Scleractinia), growing in a stressed environment. Coral Reefs 8:37-43

Fabricius KE, Klumpp DW (1995) Widespread mixotrophy in reef-inhabiting soft corals: the influence of depth, and colony expansion and contraction on photosynthesis. Mar Ecol Prog Ser 125:195-204

Fabricius KE, Genin A, Benayahu Y (1995) Flow-dependent herbivory and growth in zooxanthellae-free soft corals. Limnol Oceanogr 40:1290-1301

Falkowski PG, Dubinsky Z, Muscatine L, Porter JW (1984) Light and the bioenergetics of a symbiotic coral. Bioscience 34:705-709

Fréchette M, Butman CA, Geyer WR (1989) The importance of boundary-layer flows in supplying phytoplankton to the benthic suspension feeder, Mytilus edulis L. Limnol Oceanogr 34:19-36

Fréchette M, Aitken AE, Page L (1992) Interdependence of food and space limitation of a benthic suspension feeder: consequences for self-thinning relationships. Mar Ecol Prog Ser 83:55-62

Hastie TJ, Tibshirani RJ (1990) Generalised additive models. Chapman \& Hall, London

Helmuth BS, Sebens KP, Daniel TL (1997a) Morphological variation in coral aggregations: branch spacing and mass flux in coral tissues. J Exp Mar Biol Ecol 209:233-259

Helmuth BST, Stockwell EF, Brumbaugh DR (1997b) Morphological and environmental determinants of mass flux to corals. Proc 8th Int Coral Reef Symp, Guam 2: 1103-1108

Highsmith RC (1982) Reproduction by fragmentation in corals. Mar Ecol Prog Ser 7:207-226

Hughes TP, Tanner JE (1999) Temporal changes in population dynamics: modelling long-term decline of three Caribbean corals. Ecology 81:2250-2263

Karlson RH (1991) Fission and the dynamics of genets and ramets in clonal cnidarian population. Hydrobiologia 216: $235-240$

Lang JC (1973) Interspecific aggression by scleractinian corals 2 . Why the race is not only to the swift. Bull Mar Sci 23:260-279

Lang JC, Chornesky EA (1990) Competition between scleractinian reef corals: a review of mechanisms and effects. In: Dubinsky Z (ed) Ecosystems of the world: coral reefs. Elsevier Press, Amsterdam, p 209-252

Lewis JB (1992) Heterotrophy in corals: zooplankton predation by the hydrocoral Millepora complanata. Mar Ecol Prog Ser 90:251-256

McFadden CS (1986) Colony fission increases particle capture rates of a soft coral: advantages of being a small colony. J Exp Mar Biol Ecol 103:1-20

Monismith SG, Koseff JR, Thompson JK, O'Riordan CA, Nepf HM (1990) A study of model bivalve siphonal currents. Limnol Oceanogr 35:680-696

Muscatine L, McCloskey LR, Marian RE (1981) Estimating the daily contribution of carbon from zooxanthellae to coral animal respiration. Limnol Oceanogr 26:601-611

Muscatine L, Falkowski PG, Porter JW, Dubinsky Z (1984) Fate of photosynthetic fixed carbon in light- and shadeadapted colonies of the symbiotic coral Stylophora pistillata. Proc R Soc Lond Biol Sci 222:181-202

Newell CR (1990) The effects of mussel (Mytilus edulis, Linnaeus, 1758) position in seeded bottom patches on growth at subtidal lease sites in Maine. J Shellfish Res 9:113-118

Okamura B (1985) The effects of ambient flow velocity, colony size and upstream colonies on the feeding success of Bryozoa. II. Conopeum reticulum, an encrusting species. J Exp Mar Biol Ecol 89:69-80

Okamura B (1986) Group living and the effects of spatial position in aggregations of Mytilus edulis. Oecologia 69: 341-347

Okamura B (1988) The influence of neighbors on the feeding of an epifaunal bryozoan. J Exp Mar Biol Ecol 120: $105-123$

Okamura B (1992) Microhabitat variation and patterns of colony growth and feeding in a marine bryozoan. Ecology 73:1502-1513

Olson RR, Porter JW (1985) In situ measurement of photosynthesis and respiration in the ascidian-Prochloron symbiosis Didemnum molle. Proc 5th Int Coral Reef Symp, Tahiti 5:257-262

O'Riordan CA, Monismith SG, Koseff JR (1993) A study of concentration boundary-layer formation over a bed of model bivalves. Limnol Oceanogr 38:1712-1729

Porter JW (1976) Autotrophy, heterotrophy, and resource partitioning in Caribbean reef building corals. Am Nat 110(975):731-742

Ryland JS, Wigley RA, Muirhead A (1984) Ecology and colonial dynamics of some Pacific reef flat Didemnidae (Ascidiacea). Zool Linn Soc 80:261-282

Sanford LP, Crawford SM (2000) Mass transfer versus kinetic control of uptake across solid-water boundaries. Limnol Oceanogr 45:1180-1186

Sebens KP (1977) Autotrophic and heterotrophic nutrition of coral reef zoanthids. Proc 3rd Int Coral Reef Symp, Miami 1:397-404

Sebens KP, Johnson AS (1991) Effects of water movement on prey capture and distribution of reef corals. Hydrobiologia 226:91-102

Sebens KP, Witting J, Helmuth B (1997) Effects of water flow and branch spacing on particle capture by the reef coral Madracis mirablis (Duchassaing and Michelotti). J Exp Mar Biol Ecol 211:1-28 
Sebens KP, Grace SP, Helmuth B, Maney EJ, Miles JS (1998) Water flow and prey capture by three scleractinian corals, Madracis mirabilis, Montastrea cavernosa and Porites porites, in a field enclosure. Mar Biol 131:347-360

Shick JM (1990) Diffusion limitation and hyperoxic enhancement of oxygen consumption in zoxanthellate sea anemones, zoanthids, and corals. Biol Bull 179: $148-158$

Sorokin YI (1991) Biomass, metabolic rates and feeding of some common reef zoantharians and octocorals. Aust J Mar Fresh Res 42:729-741

Szmant AM (1991) Sexual reproduction by the Caribbean reef

Editorial responsibility: Ronald Karlson (Contributing Editor), Newark, Delaware, USA corals Montastrea annularis and Montastrea cavernosa. Mar Ecol Prog Ser 74:13-25

Tanner JE (1997) The effects of density on the zoanthid Palythoa caesia. J Anim Ecol 66:793-810

Tanner JE (1999) Density dependent population dynamics in clonal organisms: a modelling approach. J Anim Ecol 66:390-399

Tanner JE (2000) Stochastic density-dependence regulates population size in a benthic marine invertebrate. Oecologia 122:514-520

Vogel S, LaBarbera M (1978) Simple flow tanks for research and teaching. Bioscience 28:638-643

Submitted: May 1, 2000; Accepted: March 7, 2001

Proofs received from author(s): January 25, 2002 